\title{
PENGEMBANGAN HERBAL CAIR KOMBINASI DAUN SALAM [Syzygium polyanthum (Wight) Walp.] DAN KELOPAK BUNGA ROSELLA (Hibiscus Sabdariffa L.) DENGAN BERBAGAI VARIASI PEMANIS
}

\author{
Lusi Indriani*, Ike Yulia Wiendarlina, Erni Rustiani \\ Program Studi Farmasi FMIPA Universitas Pakuan Bogor \\ Email: lusi.apoteker@gmail.com
}

\begin{abstract}
ABSTRAK
Daun salam [Syzygium polyanthum (Wight) Walp] dan kelopak bunga rosella (Hibiscus sabdariffa L.) merupakantanaman yang berkhasiat untuk mengobati diabetes mellitus. Kandungan kimia yang terdapat dalam daun salam adalah minyak atsiri sitral, eugenol, tanindan flavonoid. Kandungan kimia yang pentingdari kelopak bunga rosella adalah flavonoid antosianin. Penelitian ini bertujuan menghasilkan sediaan herbal cair yang dapat digunakan untuk mengobati diabetes dengan berbagai variasi pemanis yang dapat diterima panelis dan stabil selama penyimpanan pada 3 tingkatan suhu. Sediaan dibuat dalam 3 formula. Formula A, B dan C mengandung $30 \mathrm{mg}$ sukralosa, $375 \mathrm{mg}$ stevia, dan $40 \mathrm{~g}$ madu. Berdasarkan pengujian mutu, herbal cair memiliki warna coklat (Formula A dan B) dan coklat merah (Formula C). Masing-masing sediaan memiliki aroma yang khas dan rasa yang manis. Sediaan herbal cair memiliki pH $(2,89-3,12)$, viskositas $(10,00-10,40)$ dan bobot jenis $(1,0353-1,0382)$. Hasil pengujian dengan metode uji Friedman menunjukkan bahwa formula $\mathrm{C}$ dengan pemanis madu lebih disukai panelis dengan parameter warna, aroma dan rasa. Sediaan herbal cair formula $\mathrm{C}$ lebih stabil disimpan pada suhu sejuk $\left(5-15^{\circ} \mathrm{C}\right)$ dibandingkan pada suhu kamar (15$\left.30^{\circ} \mathrm{C}\right)$ dan suhu panas $\left(40-45^{\circ} \mathrm{C}\right)$.
\end{abstract}

Kata kunci: Daun Salam, Kelopak Bunga Rosella, Pemanis, Herbal Cair.

\section{DEVELOPMENT OF LIQUID HERBAL COMBINATION Syzygium polyanthum (Wight) Walp. AND Hibiscus Sabdariffa L. FLOWER PETALS WITH SWEETENERS VARIATION}

\begin{abstract}
Syzygium polyanthum leaves and Hibiscus sabdariffa flower petals have benefits in treating diabetes mellitus. The chemical constituents of Syzygium polyanthum leaves are the volatile oil containing citral and eugenol, tannins and flavonoids. An important chemical constituent of Hibiscus sabdariffa flower petals is flavonoid antocyanin. This study aimed to make liquid herbal preparations for diabetic treatment with variations of sweeteners which could be accepted by panelists and stable during stored in 3 temperature levels. Preparations were made in 3 formulas. Formula A, B and C contained $30 \mathrm{mg}$ sucralose, $375 \mathrm{mg}$ stevia, and $40 \mathrm{~g}$ honey. Based on quality testing, liquid herbal preparations had brown color (Formula $\mathrm{A}$ and B) and red-brown color (Formula C). Each of these stocks had a distinctive aroma and a sweet taste. Liquid herbal preparations had $\mathrm{pH}$ (2.89 to 3.12), viscosity (10.00 to 10.40) and the specific gravity (1.0353 to 1.0382). The test results with Friedman test method showed that formula $\mathrm{C}$ with honey sweetener was preferred by panelist with the parameters of color, aroma and flavor. Liquid herbal preparations formula Cwhich stored at cool temperatures $\left(5-15^{\circ} \mathrm{C}\right)$ were more stable than stored at room temperature $\left(15-30^{\circ} \mathrm{C}\right)$ or at warm temperature $\left(40-45^{\circ} \mathrm{C}\right)$.
\end{abstract}

Keywords: Syzygium polyanthum leaves, Hibiscus sabdariffa flower petals, sweetener, liquid herbal preparation. 


\section{PENDAHULUAN}

Daun salam [Syzygium polyanthum (Wight) Walp.] dan Kelopak bunga rosella (Hibiscus sabdariffa L.) memiliki khasiat untuk menyembuhkan penyakit diabetes mellitus. Dosis $1,36 \mathrm{mg} / \mathrm{kg}$ BB ekstrak air daun salam dilaporkan mempunyai efek penurun kadar gula darah pada tikus yang diinduksi dengan glukosa sebesar 5,582\% (Musyrifah, Bekti, dan Fauzia, 2012). Kandungan kimia yang terdapat dalam daun salam adalah minyak atsiri $(0,05 \%)$ yang mengandung sitral, dan eugenol, sertatanin dan flavonoid. Infusa kelopak bunga rosella memiliki aktifitas menurunkan kadar gula darah tikus dengan dosis $63,5 \mathrm{mg} / 200 \mathrm{~g} \mathrm{BB}$ (Hanik, Ratih, dan Wulandari, 2011). Kandungan kimia yang penting dari kelopak bunga rosella adalah flavonoid antosianin yang bermanfaat sebagai antioksidan.

Pada penelitian ini akan dibuat formula kombinasi dari kedua bahan tersebut untuk dijadikan sediaan herbal cair yang belum ada di pasaran. Pemilihan bentuk sediaan cair ini adalah karena sediaan cair memiliki daya absorpsi yang cepat dibandingkan dengan bentuk sediaan lain, tetapi karena pada umumnya sediaan herbal cair mempunyai rasa yang kurang enak maka diperlukan penambahan variasi pemanis. Pemanis yang digunakan memiliki indeks glikemik yang rendah yaitu sukralosa, stevia dan madu (Adji, 2004; Mousumi, 2008; Wijayadan Mulyono, 2010).

Sediaan herbal cair kombinasi daun salam dan kelopak bunga rosella yang disukai panelis akan diuji stabilitasnya pada 3 kondisi suhu penyimpanan. Pengujian stabilitas meliputi pengujian secara fisika, kimia dan mikrobiologi. Penggunaan kombinasi daun salam dan kelopak bunga rosella diharapkan menghasilkan kadar flavonoid yang tinggi dalam herbal cair, karena flavonoid merupakan senyawa metabolit sekunder yang berperan dalam menurunkan kadar gula darah.

\section{METODE PENELITIAN \\ Bahan}

Bahan-bahan yang digunakan dalam penelitian ini adalah simplisia kelopak bunga rosella yang diperoleh dari Laboratorium Farmasi FMIPA UniversitasPakuan, dan daun salam yang diperoleh dari Balai Penelitian Tanaman Obat dan Aromatik (BALITTRO), yang telahdideterminasi di Herbarium Bidang Botani Pusat Penelitian Biologi, Lembaga Ilmu Pengetahuan Indonesia (LIPI), Cibinong, Bogor.Sukralosa, stevia, madu merk dagang (x), Natrium benzoat. Pelarut dan pereaksi yang digunakan pada penelitian ini meliputi air, akuades, amil alkohol, asam klorida $2 \mathrm{~N}$, gelatin $1 \%$, Natrium asetat $1 \mathrm{M}$, metanol, asam klorida encer, asam klorida $0,1 \%$, serbuk Magnesium, asam klorida, pereaksi Mayer, Bouchardat, dan Dragendorff, kuersetin, Alumunium klorida $10 \%$, buffer potasium klorida, dapar sodium asetat, natrium agar.

\section{Alat}

Alat-alat yang digunakan adalah dalam penelitian ini antara lain timbangan analitik (AND G-120 ${ }^{\circledR}$ ), oven $\left(\right.$ Memert $\left.^{\circledR}\right)$, autoklaf (Memert $^{\circledR}$ ), Silent Crusher (Heidolph), Moisture Balance (AND MX 50 ${ }^{\circledR}$ ), tanur, pH meter, spektrofotometer UV-Vis (Optizen ${ }^{\circledR}$ ), Vaccum dry $\left(\mathrm{Ogawa}^{\circledR}\right)$, lemari pendingin, viskometer Brookfield ${ }^{\circledR}$ dan alat gelas.

\section{Cara Kerja}

\section{Pembuatan Serbuk Simplisia Daun Salam}

Pembuatan simplisia daun salam dilakukan sesuai dengan prosedur standar pembuatan simplisia dengan proses pengeringan menggunakan oven $50^{\circ} \mathrm{C}$ hingga dihasilkan simplisia serbuk ukuran mesh 40. Simplisia yang diperoleh kemudian ditimbang dan disimpan dalam wadah yang kering dan bersih (Departemen Kesehatan RI, 1990 dan 1992).

\section{Karakterisasi Serbuk Simplisia Daun Salam dan Kelopak Bunga Rosella \\ a) Penetapan Kadar Air \\ Penentuan kadar air simplisia dilakukan menggunakan alat moisture balance.}


b) Penetapan Kadar Abu

Sebanyak 2-3 g simplisia ditimbang dengan seksama dimasukkan ke dalam krus platina atau silika yang sudah ditara, kemudian dipijarkan dalam tanur hingga arangnya habis, lalu didinginkan dan sisa abu ditimbang (DepartemenKesehatan RI, 2000).

\section{Pembuatan Ekstrak Kental Daun Salam}

Ekstraksi simplisia dilakukan dengan metode infundasi menggunakan $50 \mathrm{~g}$ simplisia dalam $200 \mathrm{ml}$ air. Kemudian ekstrak cair daun salam dipekatkan hingga diperoleh ekstrak kental dan ditimbang bobotnya (Musyrifah, Bekti, dan Fauzia, 2012).

\section{Uji Fitokimia}

Uji fitokimia yang dilakukan meliputi uji saponin, tannin, flavonoid, dan alkaloid. Uji saponin, flavonoid, dan alkaloid dilakukan sesuai dengan prosedur yang tercantum dalam Materia Medika Indonesia jilid III dan VI (Departemen Kesehatan RI, 1995; Sangi, Runtuwene, Simbala, dan Makang, 2008). Uji tannin dilakukan sesuai dengan prosedur Fransworth (Fransworth, 1996).

\section{Penetapan Kadar Flavonoid Total Ekstrak Daun Salam (Metode Chang) (Changet al., 2002).}

Penetapan kadar flavonoid total ekstrak daun salam dilakukan dengan terlebih dahulu menentukan panjang gelombang maksimal kuersetin dengan spektrofotometer pada panjang gelombang 380-780 nm. Lalu ditentukan waktu inkubasi optimum dan dibuat kurva standar kuersetin antara konsentrasi larutan standar kuersetin dengan nilai absorban yang diperoleh dan akan dihasilkan persamaan regresi linier $(\mathrm{y}=$ $b x+a)$. Persamaan regresi ini digunakan untuk menghitung kadar ekstrak (ppm) dengan memasukkan absorban ekstrak sebagai nilai y ke dalam persamaan. Kadar flavonoid total ditentukan menggunakan persamaan regresi dari kurva standar kuersetin (Saifudin, Rahayu, dan Teruna, 2011).

$$
\% \text { kadar }=\frac{\text { ppm } \times \text { volume } .10^{-3} \times \mathrm{fp} \times 10^{-3}}{\text { gram bobot simlpisia }} \times 100 \%
$$

\section{Penetapan Kadar Antosianin Simplisia} Kelopak Bunga Rosella (Metode $p H$ differential) (Giusti and Wrolstad, 2001).

Larutan uji dibuat dari $35 \mathrm{~g}$ serbuk simplisia rosella yang dibungkus dengan kain batis, direbus dalam air $100 \mathrm{ml}$ pada suhu 70$80^{\circ} \mathrm{C}$ selama 15 menit, setelah itu ditambahkan air hingga $250 \mathrm{ml}$ dan didiamkan sampai larutan sampel dingin. Hasil preparasi dari beberapa sampel (filtrat) akan diukur absorbansinya pada $\lambda$ maks $700 \mathrm{~nm}$ (Endang, Agus, dan Noegrohati, 2013).

Nilai absorbansi sampel dihitung dengan menggunakan persamaan :

$$
\mathrm{A}=\left[\left(\mathrm{A}_{516}-\mathrm{A}_{700}\right)_{\mathrm{pH} 1}-\left(\mathrm{A}_{516}-\mathrm{A}_{700}\right)_{\mathrm{pH} 4,5}\right]
$$

Konsentrasi Antosianin $(\mathrm{mg} / \mathrm{L})=\frac{(\mathrm{A} \times \mathrm{BM} \times \mathrm{FP} \times 1000)}{(\Sigma \times 1)}$

\section{Formulasi Herbal Cair Daun Salam dan Kelopak Bunga Rosella}

Sebanyak 0,15 g ekstrak kental daun salam dilarutkan dalam air panas $\left(100^{\circ} \mathrm{C}\right) 100$ $\mathrm{mL}$ hingga larut lalu disaring (larutan 1). Sebanyak $35 \mathrm{~g}$ simplisia kelopak bunga rosella direbus dalam kain batis dengan air sebanyak $100 \mathrm{~mL}$ pada suhu $\left(70-80^{\circ} \mathrm{C}\right)$ selama 15 menit (larutan 2). Kemudian disiapkan pemanis dengan cara melarutkan (sukralosa, stevia dan madu) masing-masing didalam air panas $\left(100^{\circ} \mathrm{C}\right) 25 \mathrm{~mL}$ hingga larut (larutan 3), kemudian saring dan masukkan ke dalam tangki pencampur. $\mathrm{Na}$ benzoat dilarutkan didalam air panas sebanyak $25 \mathrm{ml}$ (larutan 4). Larutan 3 dicampur dengan larutan 1 dan 2, lalu larutan 4 diaduk hingga homogen. Strawberry essence dilarutkandidalam air hangat $5 \mathrm{ml}$ hingga larut kemudian dicampur dengan larutan 1,2, 3, dan 4. Ditambahkan air mendidih hingga volume $250 \mathrm{~mL}$ kemudian diaduk menggunakan alat Silent Crusher. Larutan didinginkan, dimasukkan dalam wadah botol kaca yang sudah disterilkan sebelumnya. Kemudian dilakukan pasteurisasi pada suhu $70^{\circ} \mathrm{C}$ selama 15 menit menggunakan autoklaf. 
Uji Mutu Sediaan Herbal CairPenetapan Kadar Flavonoid Total dan Antosianin Herbal Cair Daun Salam dan Kelopak Bunga Rosella.

Penentuan kadar flavonoid total herbal cair dilakukan dengancarayang sama seperti penentuankadar flavonoid total pada ekstrak daun salam (Syzygium polyanthum (Wight) Walp.) dengan metode Chang (Changet al., 2002). Penentuan kadar antosianinpada herbal cairdilakukandengancara yang sama seperti penentuan kadar antosianin simplisia kelopak bunga rosella (Hibiscus safdariffa) dengan metode $\mathrm{pH}$ differential.

Tabel 1. Formulasi Herbal Cair Daun Salam dan Kelopak Bunga Rosella

\begin{tabular}{lccc}
\hline \multicolumn{1}{c}{ Bahan } & $\begin{array}{c}\text { Formula A } \\
(\mathbf{\%})\end{array}$ & $\begin{array}{c}\text { Formula B } \\
(\mathbf{\%})\end{array}$ & $\begin{array}{c}\text { Formula C } \\
(\mathbf{\%})\end{array}$ \\
\hline Ekstrak Kental Daun Salam & $0,06 \%$ & $0,06 \%$ & $0,06 \%$ \\
Serbuk Simplisia Kelopak & $14 \%$ & $14 \%$ & $14 \%$ \\
Bunga Rosella & & & \\
Sukralosa & $0,012 \%$ & - & - \\
Stevia & - & $0,15 \%$ & - \\
Madu Merk Dagang (x) & - & - & $16 \%$ \\
Natrium benzoat & $0,24 \%$ & $0,24 \%$ & $0,24 \%$ \\
Strawberry Essence & q.s & q.s & q.s \\
Air ditambahkan ad & $100 \%$ & $100 \%$ & $100 \%$ \\
\hline
\end{tabular}

Keterangan : Setiap formula dibuat sebanyak $250 \mathrm{ml} @ 25 \mathrm{ml}$ sekali minum

\section{Uji Organoleptik.}

Uji ini meliputi penilaian terhadap karakteristik sediaan herbal cair yang meliputi warna, aroma dan rasa kombinasi daun salam dan kelopak bunga rosella.

\section{Uji pH.}

Pengukuran nilai $\mathrm{pH}$ bertujuan untuk mengetahui nilai herbal cair daun salam dan kelopak bunga rosella, pengukuran menggunakan alat $\mathrm{pH}$ meter.

\section{Uji Viskositas.}

Pengukuran sediaan dilakukan dengan menggunakan viskometer Brookfield dengan kecepatan dan nomor spindle tertentu hingga mencapai torsi $100 \%$ pada suhu kamar.

\section{Uji Bobot Jenis.}

Penetapan bobot jenis dilakukan dengan menggunakan piknometer.

\section{Uji Cemaran Mikroba.}

Pengujian ini dilakukan untuk mengetahui seberapa besar cemaran bakteri pada sediaan herbal cair daun salam dan kelopak bunga rosella pada minggu ke-0 dan minggu ke-8. Metode yang digunakan adalah uji angka lempeng total, dengan menghitung koloni bakteri pada serial pengenceran formula herbal cair. Hasil pengujian dibandingkan dengan standar uji cemaran mikroba (Badan Standarisasi Nasional, 2009).

\section{Uji Hedonik.}

Uji hedonik dilakukan terhadap 20 orang panelis dengan kriteriausia $>35$ tahun dan sebelumnya para panelis tidak mengkonsumsi makanan atau minuman yang dapat mempengaruhi penilaian. Para panelis diminta mencicipi dan menilai warna, rasa dan aroma dari sampel sediaan herbal cair. Para panelis diharapkan untuk mengisi kertas kuisioner yang telah disediakan. Waktu selang untuk mencicipi formula 1 dengan yang lain kurang lebih 1 menit dan setelah mencicipi sediaan herbal cair diharapkan panelis minum air putih atau berkumur sebelum mencicipi formula lainnya.

Parameter uji hedonik diuji meliputi rasa, warna dan aroma yang masing-masing akan mendapat penilaian 1: sangat tidak suka, 2: tidak suka, 3: cukup suka, 4: suka, 5: sangat suka. Hasil uji hedonik dianalisis menggunakan SPSS.17 dengan rancangan RAL (Rancangan Acak Lengkap) (Santoso, 2009). 


\section{Uji Stabilita}

Evaluasi kestabilan sediaan herbal cair dilakukan dalambotolkaca untuk mengetahui kualitas sediaan herbal cair berdasarkan parameter secara fisika (organoleptik, $\mathrm{pH}$, viskositas dan bobot jenis), secara kimia (uji kadar flavonoid total dan kadar antosianin), dan secara mikrobiologi (uji cemaran mikroba). Uji stabilita dilakukan untuk sediaan sirup yang terpilih berdasarkan uji hedonik. Evaluasi dilakukan pada 3 tingkatan suhu, yaitu $15^{\circ}-30^{\circ} \mathrm{C}$ (suhu kamar), $5^{\circ}-15^{\circ} \mathrm{C}$ (suhu sejuk) dan $40^{\circ}-45^{\circ} \mathrm{C}$ (suhu panas) selama delapan minggu dengan pengambilan sampel untuk uji setiap 2 minggu. Jumlah botol yang digunakan adalah 5 kali 3 botol sehingga total jumlah botol yang diperlukan adalah 15 botol.

\section{HASIL DAN PEMBAHASAN}

Hasil identifikasi tumbuhan yang dilakukan di Herbarium Bogoriense Bidang Botani Pusat Penelitian Biologi-LIPI, Cibinong, Bogor menunjukkan bahwa identitas tumbuhan salam adalah Syzygium polyanthum (Wight) Walp. suku Myrtaceae dan tumbuhan rosella adalah Hibiscus sabdariffa L. Suku Malvaceae. Karakteristik serbuk simplisia daun salam adalah berwarna hijau terang, aroma khas, dan rasa agak sedikit ketir dan pedas. Sedangkan karakteristik serbuk simplisia kelopak bunga rosella adalah berwarna merah, aroma sangat khas, dan rasa asam. Rendemen serbuk simplisia daun salam yang diperoleh adalah sebesar 15,43\% (Mardiah dkk., 2009).

Penentuan kadar air bertujuan untuk memperkecil pertumbuhan mikroorganisme dalam serbuk simplisia. Hal ini terkait dengan kemurnian dan adanya kontaminan dalam simplisia tersebut. Dengan demikian, penghilangan kadar air hingga jumlah tertentu berguna untuk memperpanjang daya tahan bahan selama penyimpanan. Pada umumnya syarat kadar air simplisia kurang dari 5\%. Dari hasil yang diperoleh penentuan kadar air menggunakan metode moisture balance, kadar air simplisia daun salam adalah sebesar 3,87\% dan kadar air serbuk simplisia kelopak bunga rosella adalah sebesar $4,215 \%$. Hasil ini menunjukan bahwa serbuk simplisia daun salam dan kelopak bunga rosella telah memenuhi syarat yaitu kurang dari $10 \%$ (Mardiah dkk., 2009). Penentuan kadar abu bertujuan untuk mengetahui atau mengidentifikasi kadar zat anorganik dan mineral dalam simplisia. Parameter kadar abu merupakan pernyataan dari jumlah abu fisiologik bila simplisia dipijar hingga seluruh unsur organik hilang. Prinsipnya adalah bahan dipanaskan pada temperatur $800^{\circ} \mathrm{C}$ dimana senyawa organik dan turunanya terdekstrusi dan menguap hingga tersisa unsur mineral organik. Pengujian kadar abu pada serbuk simplisia daun salam sebesar 3,125\%, persyaratan kadar abu serbuk simplisia daun salam berdasarkan Materia Medika Indonesia adalah tidak lebih dari 5\% (Departemen Kesehatan RI, 1980). Pengujian kadar abu pada serbuk simplisia kelopak bunga rosella sebesar 7,515\%. Hasil yang diperoleh memenuhi syarat yaitu tidak lebih dari $11 \%$ (Mardiah dkk., 2009).

\section{Ekstrak Kental Daun Salam dan Rebusan Kelopak Bunga Rosella}

Ekstrak kental daun salam diperoleh melalui metode infundasi yaitu dengancara mengekstraksi sebanyak $400 \mathrm{~g}$ serbuk simplisia dalam $1600 \mathrm{ml}$ air. Ekstrak cair kemudian dipekatkan menggunakan alat vaccum dry, diperoleh ekstrak kental sebanyak 42,96 g sehingga diperoleh rendemen ekstrak sebesar 10,74 \% (Departemen KesehatanRI, 1980). Sebanyak $35 \mathrm{~g}$ simplisia kelopak bunga rosella direbus dalam kain batis dengan air sebanyak $100 \mathrm{ml}$ pada suhu $\left(70-80^{\circ} \mathrm{C}\right)$ selama 15 menit. Penggunaan kain batis bertujuan agar antosianin yang terkandung dalam kelopak bunga rosella tidak rusak, karena antosianin tidak stabil pada suhu tinggi.

Penentuan konsentrasi bahan aktif adalah berdasarkan penelitian sebelumnya dimana dosis efektif ekstrak kental daun salam sebagai antidiabetes pada tikus adalah $1,36 \mathrm{mg} / \mathrm{kgBB}$ (Musyrifah, Bekti dan Fauzia, 2012), setelah dikonversi ke dosis manusia adalah $0.06 \%$. Sedangkan dosis efektif infusa kelopak bunga rosella sebagai antidiabetes 
pada tikus adalah $62,5 \mathrm{mg} / 200 \mathrm{gBB}$ (Hanik, Ratih dan Wulandari, 2011), setelah dikonversi ke dosis manusia adalah $14 \%$.

\section{Hasil Pengujian Fitokimia}

Pengujian fitokimia dilakukan secara kualitatif untuk menentukan kandungan metabolit sekunder yang terkandung dalam sampel. Hasil pengujian fitokimia terhadap serbuk simplisia daun salam dan kelopak bunga rosellaadalah positifmengandung alkaloid, flavonoid, saponin dan tanin.

\section{Penetapan Kadar Flavonoid Total Ekstrak Daun Salam}

Penentuan jumlah flavonoid dari ekstrak daun salam dilakukan menggunakan metode Chang secara kolorimetri yang mempunyai prinsip pengukuran berdasarkan pembentukan warna (Changet al., 2002). Prinsip penetapan flavonoid dengan metode kolorimeter $\mathrm{AlCl}_{3}$ adalah pembentukan kompleks antara $\mathrm{AlCl}_{3}$ dengan gugus keto pada atom $\mathrm{C}-4$ dan juga dengan gugus hidroksi pada atom C-3 atau C-4 yang bertentangga dari flavon dan flavonol. Sehingga metode ini dapat digunakan untuk menentukan jumlah flavonoid golongan flavon dan flavonol.

Tabel 2. Optimasi Waktu Inkubasi Kuersetin

\begin{tabular}{cc}
\hline $\begin{array}{c}\text { Waktu } \\
\text { (menit) }\end{array}$ & Absorbansi \\
\hline 5 & 0,183 \\
10 & 0,191 \\
15 & 0,225 \\
20 & 0,396 \\
$\mathbf{2 5}$ & $\mathbf{0 , 3 9 1}$ \\
30 & 0,388 \\
\hline
\end{tabular}

\section{Penetapan Kadar Antosianin Serbuk Simplisia Kelopak Bunga Rosella}

Penentuan kadar antosianin serbuk simplisia kelopak bunga rosella dilakukan dengan metode perbedaan $\mathrm{pH} \quad(\mathrm{pH}$
Pada tahap awal pengukuran flavonoid diawali dengan menentukan panjang gelombang maksimum untuk mendapatkan serapan maksimum dari larutan. Panjang gelombang untuk penentuan kadar flavonoid berkisar 380 - $780 \mathrm{~nm}$. Panjang gelombang maksimum yang diperoleh setelah pengujian adalah $430 \mathrm{~nm}$. Penentuan waktu inkubasi optimum dilakukan pada beberapa titik waktu yaitu 5, 10, 15, 20, 25, 30 menit (Tabel 2). Penentuan waktu inkubasi optimum dilakukan untuk mengetahui waktu penyimpanan yang akan memberikan serapan stabil sehingga suatu zat agar dapat bereaksi secara maksimal. Setelah pengujian waktu inkubasi optimum yang diperoleh adalah menit ke-25 dengan nilai absorbansi 0,391.

Pengukuran kurva kalibrasi dibuat dengan deret konsentrasi 2, 4, 6, 8, 10 ppm untuk mendapatkan persamaan linearitas antara absorbansi dan konsentrasi. Persamaan linearitas $\mathrm{y}=0,082 \mathrm{x}+0,038$ dengan nilai koefesien relasi $\mathrm{r}=0,999$ yang berarti ada korelasi antara nilai absorbansi dengan konsentrasi (Gambar 1). Berdasarkan perhitungan kadar flavonoid total untuk ekstrak kental daun salam yaitu sebesar pada ulangan (I) $0,1418 \%$ dan pada ulangan (II) $0,1432 \%$ dengan rata-rata $0,1425 \%$.

Differential) (Giusti and Wrolstad, 2001) yaitu pada $\mathrm{pH}$ 1,0 dan $\mathrm{pH} 4,5$. Sampel yang digunakan adalah hasil rebusan kelopak bunga rosella dengan pelarut air, digunakan pelarut air karena antoasianin merupakan senyawa polar. Penetapan konsetrasi antosianin dengan metode ini dikarenakan pada $\mathrm{pH}$ 1,0 antosianin membentuk senyawa oxonium (kation flavilium) yang berwarna dan pada $\mathrm{pH}$ 4,5 membentuk karbinol tak berwarna (Saifudin, Rahayu, dan Teruna, 2011). Sampel diuji dengan menggunakan spektrofotometer UV-Vis pada panjang gelombang $516 \mathrm{~nm}$ dan $700 \mathrm{~nm}$. Hasil penetapan kadar antosianin yang diperoleh adalah sebesar 9,257 mg/kg. 


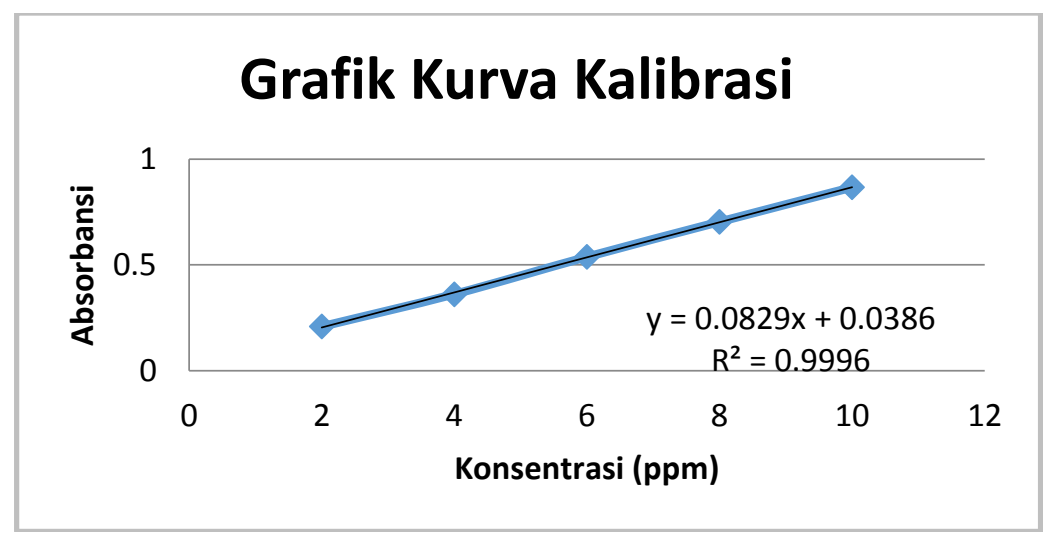

Gambar 1. Kurva Linieritas

\section{Hasil Uji Kesukaan}

Uji hedonik atau uji kesukaan bertujuan untuk menilai suatu produk secara organanoleptik yaitu meliputi warna, aroma dan rasa. Dalam uji hedonik panelis diminta tanggapan pribadinya mengenaik kesukaan atau ketidaksukaan. Uji hedonik dilakukan pada ketiga formula dengan variasi pemanis yang berbeda. Formula A dengan pemanis sukralosa, Formula B dengan pemanis stevia dan Formula $\mathrm{C}$ dengan pemanis madu. Pemanis yang digunakan adalah pemanis yang mempunyai nilai indeks glikemik rendah.

Panelis yang dapat mencoba adalah panelis yang memiliki kriteria umur diatas 35 tahun. Hasil uji kesukaan dianalisis dengan SPSS.17 dengan metode friedman test dimana parameter warna dan rasa memberikan pengaruh yang nyata pada setiap formula, sedangkan parameter aroma tidak memberikan pengaruh pada setiap formula. Dapat disimpulkan bahwa panelis menyukai formula $\mathrm{C}$ dengan pemanis madu (Tabel 3 dan 4).

Tabel 3. Output SPSS. 17 Uji Hedonik

\begin{tabular}{llll}
\hline \multicolumn{1}{c}{ Formula } & \multicolumn{1}{c}{ Warna } & \multicolumn{1}{c}{ Aroma } & \multicolumn{1}{c}{ Rasa } \\
\hline A sukralosa & 1.60 & 1.88 & 1.80 \\
B stevia & 1.68 & 1.95 & 1.63 \\
C madu & 2.73 & 2.18 & 2.58 \\
\hline
\end{tabular}

Tabel 4. Hasil Uji Mutu Herbal Cair

\begin{tabular}{cccc}
\hline Parameter & Formula A & Formula B & Formula C \\
\hline Rasa & Manis & Manis & Manis \\
Aroma & Khas & Khas & Khas \\
Warna & Coklat & Coklat & $\begin{array}{c}\text { Coklat } \\
\text { Kemerahan }\end{array}$ \\
pH & 3,12 & 3,09 & 2,89 \\
Viskositas & 10,00 & 10,20 & 10,40 \\
$\begin{array}{c}\text { (cps) } \\
\text { Bobot jenis } \\
\text { (g/ml) }\end{array}$ & 1,0353 & 1,0382 & 1,0361 \\
\hline
\end{tabular}

\section{Hasil Uji Stabilita}

Pengujian ini bertujuan untuk melihat stabilitas fisik dari sediaan herbal cair pada kondisi penyimpanan dengan suhu yang berbeda. Pengujian stabilitas fisik dilakukan dengan menyimpan herbal cair pada suhu yang berbeda yaitu, suhu sejuk $\left(5-15^{\circ} \mathrm{C}\right)$, suhu kamar $\left(15-30^{\circ} \mathrm{C}\right)$, dan suhu panas $\left(40-45^{\circ} \mathrm{C}\right)$ selama 8 minggu. Uji stabilita dilakukan pada formula $\mathrm{C}$ dengan pemanis madu. Selama pengujian stabilitas dilakukan pengujian untuk parameter fisika dan kimia. Parameter fisika yang dilakukan antara lain uji organoleptik, uji $\mathrm{pH}$, uji viskositas, uji berat jenis dan uji cemaran mikroba. Parameter kimia yang dilakukan adalah uji kadar flavonoid total ekstrak daun salamdanherbal cair, uji kadar antosianin serbuk simplisia kelopak bunga roselladan herbal cair.

\section{Hasil Uji Stabilita Parameter Organoleptik Pengujian organoleptik adalah} pengujian yang didasarkan pada proses pengindraan. Pada pengujian parameter organoleptik meliputi warna, aroma dan rasa. Pengujian organoleptik dilakukan setiap 2 minggu sekali selama 8 minggu. 
Penampilan fisik dari sediaan herbal cair menunjukan perubahan fisik pada minggu ke-6 pada suhu kamar dan suhu panas, hal ini disebabkan adanya degradasi dari antosianin yang terkandung dalam kelopak bunga rosella. Sedangkan pada suhu sejuk lebih stabil dari minggu ke-0 sampai minggu ke-8.

\section{Hasil Uji Stabilita Parameter pH}

Pada pengujian parameter $\mathrm{pH}$ sediaan herbal cair selama stabilitas. Selama stabilitas sediaan herbal cair mengalami kenaikan $\mathrm{pH}$. Akan tetapi pada penyimpanan suhu sejuk relatif stabil. Kenaikan $\mathrm{pH}$ pada sediaan herbal cair karena diakibatkan oleh adanya reaksi-reaksi enzimatis yang terjadi dalam sediaan selama penyimpanan.

Berdasarkan hasil uji herbal cair nilai $\mathrm{pH}$ yang diperoleh adalah asam kuat, nilai $\mathrm{pH}$ asam kuat dihasilkan dari kandungan vitamin $\mathrm{C}$ yang terdapat dalam kelopak bunga rosella. Berdasarkan nilai SD perubahan $\mathrm{pH}$ pada suhu sejuk tidak terlalu besar dibandingkan dengan suhu kamar dan suhu panas.

\section{Hasil Uji Stabilita Parameter Viskositas}

Viskositas adalah ukuran suatu ukuran yang menyatakan berapa daya tahan dari aliran yang diberikan oleh suatu cairan. Pengujian parameter viskositas menggunakan alat brookfield dengan spindle 2 dengan kecepatan 50 RPM. Dipilih spindle 2 karena diperoleh nilai torsi yang cukup baik. Pada viskositas dipengaruhi dengan berat jenis dan temperatur. Viskositas berbanding lurus dengan berat jenis dan berbanding terbalik dengan temperatur artinya semakin tinggi temperatur maka nilai viskositas akan menurun begitupun sebaliknya. Berdasarkan SD nilai viskositas pada suhu sejuk tidak terlalu tinggi dibandingkan dengan suhu kamar dan suhu panas, hal ini menunjukan bahwa pada suhu sejuk nilai viskositasnya relatif lebih stabil.

\section{Hasil Uji Stabilita Parameter Bobot Jenis}

Bobot jenis adalah suatu besaran yang menyatakan perbandingan anatara massa (gram) dengan volume (ml). Pada pengujian bobot jenis menggunakan alat piknometer dimana prinsipnya yaitu penentuan masssa cairan dan penentuan ruangan yang ditempati cairan tersebut. Berat jenis dipengaruhi oleh besar kecilnya nilai kerapatan suatu cairan, dimana semakin besar kerapatan maka akan semakin besar nilai berat jenisnya. Berdasarkan hasil SD nilai bobot jenis dari minggu ke-0 sampai ke-8 tidak menunjukan pengaruh yang nyata pada setiap kondisi penyimpanan.

\section{Hasil Uji Stabilita Parameter Cemaran Mikroba}

Pada pengujian ini diketahui seberapa besar cemaran mikroba pada sediaan herbal cair. Metode yang digunakan adalah uji angka lempeng total, dengan menghitung koloni bakteri pada serial pengenceran formula herbal cair. Hasil pengujian ini akan dibandingkan dengan standar uji cemaran mikroba (Badan Standarisasi Nasional, 2009).

Berdasarkan hasil pengujian pada minggu ke-0 hasil yang diperoleh masih memenuhi syarat Standar Nasional Indonesia. Pada minggu ke-8 pada penyimpanan suhu panas menunjukan jumlah angka kontaminasi mikroba yang masih diambang batas persyaratan. Menurut Badan Standarisasi Nasional (SNI 7388:2009) persyaratan untuk sirup yang berkhasiat yaitu sebesar $<1 \times 10^{4}$ koloni/ml. Terjadinya peningkatan angka lempeng total yang tidak memenuhi standar batas cemaran mikroba pada herbal diduga karena kurangnya konsentrasi bahan pengawet natrium benzoat yang digunakan.

\section{Hasil Uji Flavonoid Total dan Antosianin Herbal Cair}

Kadar flavonoid total dan antosianin ditentukan dengan melihat nilai absorbansi dari masing-masing herbal cair yang disimpan pada kondisi suhu penyimpanan yang berbeda. Berdasarkan hasil pengujian kadar flavonoid total yang terdapat dalam herbal cair mengalami penurunan di setiap pengujian, dimana pengujian dilakukan pada minggu ke-0, minggu ke-4 dan minggu ke-8 (Tabel 5). Adanya penurunan kadar disebabkan adanya proses pemanasan pada 
saat proses pasteurisasi dan proses penyimpanan. Dilihat dari hasil pengujian kadar flavonoid pada kondisi penyimpanan suhu sejuk relatif stabil.

Pada pengujian antosianin herbal cair dilakukan sama seperti simplisia kelopak bunga rosella. Berdasarkan hasil uji kadar antosianin yang diperoleh setiap kali pengujian mengalami penurunan. Suhu memiliki peranan dan pengaruh yang sangat penting terhdap kestabilan antosianin. Suhu penyimpanan maupun suhu proses pengolahan dapat mempengaruhi proses degradasi antosianin (Hendry and Houghton, 1996). Semakin meningkatnya suhu dapat menyebabkan hilangnya glikosil pada antosianin dengan hidrolisis ikatan glikosidik. Aglikon yang dihasilkan kurang stabil dan menyebabkan hilangnya warna pada antosianin. Berdasarkan hasil Standar Deviasi (SD) kadar flavonoid total pada setiap suhu penyimpanan tidak memberikan pengaruh yang terlalu signifikan. Berdasarkan hasil SD kadar antosianin, nilai SD pada suhu sejuk lebih kecil dibandingkan dengan suhu kamar dan suhu lebih tinggi.

\section{Tabel 5. Hasil Uji Flavonoid Total dan Antosianin Herbal Cair}

\begin{tabular}{|c|c|c|c|c|c|c|c|c|}
\hline \multirow[b]{2}{*}{ Suhu } & \multicolumn{3}{|c|}{ Flavonoid Total (\%) } & \multirow[b]{2}{*}{ SD } & \multicolumn{3}{|c|}{ Antosianin (mg/L) } & \multirow[b]{2}{*}{ SD } \\
\hline & $\mathbf{0}$ & 4 & 8 & & $\mathbf{0}$ & 4 & 8 & \\
\hline $\begin{array}{c}\text { Suhu sejuk } \\
\left(5^{\circ}-15^{\circ} \mathrm{C}\right), \\
\left(\text { suhu nyata } 5^{\circ} \mathrm{C}\right) \\
\end{array}$ & 0,5533 & 0,5436 & 0,5346 & $\pm 0,00935$ & 5,9132 & 5,4362 & 4,8562 & $\pm 0,5293$ \\
\hline $\begin{array}{c}\text { Suhu kamar } \\
\left(15^{\circ}-30^{\circ} \mathrm{C}\right), \\
\left(\text { suhu nyata } 27^{\circ} \mathrm{C}\right)\end{array}$ & 0,5533 & 0,5105 & 0,4773 & $\pm 0,0381$ & 5,9132 & 5,3114 & 4,7044 & $\pm 0,6044$ \\
\hline $\begin{array}{c}\text { Suhupanas } \\
\left(40^{\circ}-45^{\circ} \mathrm{C}\right), \\
\left(\text { suhu nyata } 40^{\circ} \mathrm{C}\right)\end{array}$ & 0,5533 & 0,3972 & 0,3792 & $\pm 0,0957$ & 5,9132 & 4,2491 & 2,1245 & $\pm 1,8990$ \\
\hline
\end{tabular}




\section{SIMPULAN DAN SARAN \\ Simpulan}

Ekstrak daun salam dan kelopak bunga rosella dapat dibuat sediaan herbal cair. Formula $\mathrm{C}$ dengan pemanis madu yang paling disukai panelis dengan parameter warna, aroma dan rasa. Sediaan herbal cair Formula $\mathrm{C}$ lebih stabil disimpan pada suhu sejuk $\left(5^{\circ} \mathrm{C}-15^{\circ} \mathrm{C}\right)$ dibandingkan pada suhu kamar $\left(15^{\circ} \mathrm{C}-30^{\circ} \mathrm{C}\right)$ dan suhu panas $\left(40^{\circ} \mathrm{C}-45^{\circ} \mathrm{C}\right)$.

\section{Saran}

Saran untuk penelitian selanjutnya adalah agar dilakukan penggantian jenis pengawet yang dapat mencegah pertumbuhan mikroba, danuji invivo untuk herbal cair pada hewan coba sebagai alternatif pengobatan diabetes.

\section{DAFTAR PUSTAKA}

Adji, S. 2004. Khasiat dan Manfaat Madu Herbal. Agromedia Pustaka, hal. 10.Jakarta.

BadanStandarisasiNasional. 2009. Batas maksimum cemaran mikroba dalam pangan.

BadanStandarisasiNasional. http://sisni.bsn.go.id/index.php/sni _main/sni/detail_sni/9806

Departemen Kesehatan RI. 1990. Cara Pembuatan Simplisia. Jakarta.

Chang, C, M. Yan, H. Wen dan J. Chern. 2002. Estimation of total content in propolis by two complementary colorimetric methods. Journal of food and drug analysis. 10 (3)179.

Departemen Kesehatan Republik Indonesia. 1980. Materia Medika Indonesia, Jilid IV. Jakarta.

.1992 Cara Pembuatan Obat Tradisional Yang Baik. Jakarta.

_. 1995. Materia Medika Indonesia, Jilid VI. Jakarta.

_. 2000. Parameter Standar Umum Ekstrak Tumbuhan Obat. Jakarta.

Endang, L. Agus, dan S. Noegrohati. 2013. Pengembangan Sediaan Eksfolian dan Uji Aktivitas Antioksidan Kelopak Bunga Rosella Dalam Upaya Melawan Radikal Bebas. Prosiding Seminar Nasional Perkembangan Terkini Sains Farmasi dan KlinikIII 2013. ISSN: 2239-2592.

Fransworth, N.R. 1996. Biological and Phytochemical Screening of Plants. Journal of Pharmaceutical Science, 199655 (3).

Giusti, M. M. And R.E. Wrolstad. 2001. Characterization and Measurement of Anthocyanins by UV-Visible Spectroscopy, Journal of Current protocols in food Analytical.

Hanik, A., Ratih, dan Wulandari. 2011. Uji Antidiabetik Infusa Kelopak Bunga Rosella (Hibiscus sabdariffa L.) pada Tikus Putih Jantan Galur Wistar yang Diinduksi Glukosa.Universitas Muhamadiyah. Semarang.

Hendry, G. A. F. and J.D. Houghton. 1996.Natural Food Colorant2nd Edition. Blackie Academic and Professional. London.

Mardiah, Sawarni, W. Ashadi, dan A. Rahayu. 2009. Budidaya dan pengolahan rosella simerah segudang manfaat. Agromedia Pustaka, Jakarta. Hal 77-83.

Mousumi, D. 2008. Clonal propagation and antimicrobial activity of an endemic medicinal plant Stevia rebaudiana. Journal of Medicinal Plants Research. 2(2): 045-051.

Musyrifah, S., Bekti, dan Fauzia. 2012.Pastiles Daun Salam (Eugenia Polyantha W.). Universitas Gajah Mada. Yogyakarta.

Saifudin, A., V. Rahayu, dan H.Y. Teruna. 2011. Standarisasi Bahan Obat Alam. Yogyakarta.Graha Ilmu.

Sangi, M., M.R.J. Runtuwene, H.E.I. Simbala, V. Makang. 2008. Analisis Fitokimia Tumbuhan Obat di Kabupaten Minahasa Utara. Chemistry Progress. 
Santoso, S.2009. Panduan lengkap menguasai statistik dengan SPSS 17. PT. Elex Media Komputindo. Jakarta.
Wijaya,H.C. dan N. Mulyono. 2010. Bahan Tambahan Pangan"Pemanis". IPB Press 